\title{
COMBATE À DESERTIFICAÇÃO E A COP DOS POBRES
}

\section{LUCHA CONTRA LA DESERTIFICACIÓN Y LA COP DE LOS POBRES}

\section{DESERTIFICATION COMBAT AND THE COP OF THE POOR}

\author{
Darly Henriques da SILVA ${ }^{1}$
}

\begin{abstract}
RESUMO: O artigo discute a Convenção das Nações Unidas de Combate à Desertificação (UNCCD) comparando-a com outras convenções criadas por ocasião da Conferência do Rio de Janeiro sobre Meio Ambiente de 1992 e mostra algumas dificuldades para implementá-la. Embora a Conferência das Partes (COP) sobre desertificação ocorra regularmente desde 1997 houve pouco progresso quanto a resultados e este ponto é explorado no trabalho. As conclusões do presente trabalho cobrem cinco aspectos interdependentes: econômico; político e geopolítico; científico; e ressalta o papel da mídia e estratégia e de política externa do Brasil.
\end{abstract}

Palavras-chave: Desertificação, Convenções da ONU, Cooperação Internacional

RESUMEN: El artículo aborda la Convención de las Naciones Unidas de Lucha contra la Desertificación (UNCCD) comparándola con otras convenciones creadas durante la Conferencia de Río de Janeiro sobre el Medio Ambiente de 1992, y muestra algunas dificultades para implementarlo. Aunque la Conferencia de las Partes (COP) sobre la desertificación ocurre regularmente desde 1997 ha habido poco progreso en los resultados y este punto es explorado en el trabajo. Los hallazgos de este estudio abarcan cinco aspectos interdependientes: la económica; política y geopolítica; científica; y hace hincapié en el papel de los medios de comunicación y la estrategia y la política exterior de Brasil

Palabras clave: Desertificación, Los convenios de las Naciones Unidas, La Cooperación Internacional

\begin{abstract}
The article discusses the United Nation Convention to Combat Desertification comparing it with other conventions issued from the 1992 Environment Conference held in Rio de Janeiro and shows some of the difficulties to implement it. Although the Conference of the Parties (COP) on Desertification holds regularly sessions since 1997, little progress can be assigned to the results, and this point is explored in the article. The findings of this study cover five interdependent aspects: economic; political and geopolitical; scientific; and emphasizes the role of media and strategy and foreign policy of Brazil.
\end{abstract}

Key-words: Desertification, UN Conventions, International Cooperation

\footnotetext{
${ }^{1}$ CNPq (Coordenação Geral Cooperação Internacional), Graduação (UnB) e Mestrado (CBPF) em Física; Doutor em Economia (Universidade de Paris, Panthéon Sorbonne); Visiting Scholar C,T\&I e Espaço (George Washington University), Analista de C\&T Senior III do CNPq, Coordenador Geral de Meteorologia, Climatologia e Hidrologia. MCTI (2004/ 2012). E-mail: darlyhs@ hotmail.com
} 


\section{Introdução}

A comunidade internacional testemunha há anos a situação dramática vivida por populações de diferentes países africanos, assolados pela seca, guerras e fome. Desde a década de 1970, a mídia passou a divulgar imagens do deslocamento de milhares de refugiados africanos em busca de sobrevivência, e fugindo dessas catástrofes.

Tais tragédias humanas persistem no Século XXI. Em setembro de 2011, a zona do Chifre da África (Somália, Etiópia, Djbouti e Eritréia) testemunhou a perpetuação da seca prolongada e suas terríveis conseqüências. Movimentos de fuga das secas devastadoras se estendem ao Quênia onde milhares de imigrantes dos países vizinhos se amontoam no campo de refugiados de Dadaab ( $3^{\text {a }}$ maior cidade do Quênia), considerado o maior do mundo. Construído há 20 anos, este acampamento com capacidade para abrigar 90 mil pessoas é ocupado por 400 mil habitantes. Em julho de 2011, 40 mil somalis chegaram a este campo de refugiados da desertificação. ${ }^{2}$ A situação política da Somália é complicada porque o país é governado por diversos clãs, prejudicando a ajuda à população por parte de organizações internacionais. Faltam escolas, hospitais e segurança. Por isso, o êxodo para o Quênia, afirmou Rui Gutierrez, voluntário brasileiro da ONG Médicos sem Fronteiras. ${ }^{3}$

Este é o ambiente de uma parte dos países africanos vítimas da desertificação. De fato, grandes movimentos migratórios e intensos processos de devastação ambiental começaram a ser detectados em toda a África na década de 70, especialmente na região semiárida, ao sul do deserto do Sahara, conhecida como Sahel. O cenário se caracterizava pela pobreza, fome e destruição de recursos naturais (água, vegetação e solo). Tal destruição passou a ser entendida como desertificação.

A Convenção das Nações Unidas de Combate à Desertificação (UNCCD) foi criada como o fórum internacional de discussão e proposição de ações para enfrentar a desertificação que afeta um número importante da população mundial, a mais desprovida do planeta. $\mathrm{O}$ problema não é restrito à África, embora seja mais grave neste continente. Essa Convenção, bem como outras das Nações Unidas, tem na Conferência das Partes (COP) seu órgão maior de governança.

\footnotetext{
${ }^{2}$ http://www.miaf.org.br/noticias.asp?idnoticia=254\&noticia=chifre-da-\%E1frica:-o-tr.... Consulta em 26/10/2011.

${ }^{3}$ Folha de São Paulo, Médico em campo, p. A18 Mundo,17/01/2011.
} 
Apesar de estudos preliminares apontarem para os países em desenvolvimento e localizados em regiões áridas e semiáridas como os mais afetados pelas mudanças climáticas, as questões relacionadas à desertificação não conseguiram mobilizar as sociedades tanto quanto o impacto dessas mudanças sobre o Ártico e a extinção dos ursos polares, ou a subida ameaçadora dos oceanos causada pelo aquecimento global e a destruição de países insulares e metrópoles litorâneas.

Desde 1980, a seca e a fome associadas à desertificação dizimaram mais de 580 mil pessoas, afetando mais de 1,6 bilhão de seres humanos. ${ }^{4}$ No Nordeste Brasileiro, a seca em 2012 foi a mais destruidora dos últimos 40 anos com 500 municípios aonde foi decretado "estado de emergência". Biomas nas regiões áridas e semiáridas sujeitos a esse fenômeno e processo são muito vulneráveis e exigem ações emergenciais e outras mais definitivas para impedir a sua destruição.

O presente trabalho apresenta um breve histórico e motivação para a criação da Convenção de Combate à Desertificação, o seu pioneirismo em conjunto com a Agenda 21, bem como as demais convenções aprovadas na Rio92. Ademais, apresenta alguns dos desafios que se colocam com vistas a se enfrentar os fenômenos climáticos extremos como a desertificação, além da falta de prioridade e empenho de tratar as questões relacionadas a este tema por parte da comunidade internacional e nacional.

\section{Tecnologia a serviço dos "excluídos" climáticos}

As ações humanitárias relacionadas aos refugiados da seca extrema dispõem de imagens de satélites, úteis, na medida em que os espaços que os acolhem devem estar situados em local com disponibilidade de água, embora sejam também países pobres e afetados pela seca. Os conflitos por água com impacto sobre a disponibilidade por alimento tornaram-se comuns no Século XX em regiões onde há escassez desse recurso natural, com registros a partir da década de 70, e prosseguindo no século atual com migração das populações afetadas.

Campos individuais de refugiados, vilas locais, e redes de estradas são detectados, e mapeados por meio de uma inspeção visual de imagens de satélite, representando uma ajuda da tecnologia em prol das sociedades, e uma ferramenta para o monitoramento das migrações e para os tomadores de decisão.

\footnotetext{
${ }^{4}$ http://www.ofuturoquenosqueremos.org.br/disasters.php, consulta em 20/06/2012
} 
O órgão das Nações Unidas responsável pelas operações de assistência humanitária, a UNHCR, tem inúmeras atividades relacionadas ao meio ambiente das áreas que recebem refugiados na África. Uma delas consiste no manejo e no uso sustentável dos recursos naturais e de florestas em torno dos campos de Dadaab, no Quênia. Por exemplo, as imagens do satélite de alta resolução Ikonos do campo de refugiados Ilfo mostra cinturões verdes de árvores plantadas como retângulos nas bordas dos campos. (BJORGO, 2001). Esta informação é importante para a definição de estratégias e de novas ações.

\section{Desertificação: um processo não exclusivo da África}

Após a constatação da dramática situação da África com relação à desertificação, agravada por guerras, genocídio e miséria das populações, a comunidade internacional percebeu que a desertificação não existia apenas nesta parte do planeta, mas se estendia a todos os continentes, exceto a Antártica. Esse fenômeno ocorria principalmente em países que possuem climas de tipo árido e semiárido. Era o início de um mapeamento das zonas afetadas pelo problema, e do entendimento de que a desertificação deveria ser tratada como um tema em escala mundial, e, por isso, precisava ser enfrentado com ações de caráter global. Ademais não somente a prevenção seria importante, mas o combate à desertificação se tornara importante dado ao estado de degradação que se encontravam determinadas terras.

As Nações Unidas convocaram então uma Conferência Internacional para o Meio Ambiente Humano em Estocolmo em 1972. Nela se discutiram inúmeros temas ambientais, incluindo a catástrofe africana representada pela grande seca do Sahel (1967-1970) e os problemas de desertificação. Durante esta conferência, quando se institui o Dia Mundial do Meio Ambiente - 5 de junho, foi constatada a necessidade de um evento para tratar a desertificação mais detalhadamente.

Seguiu-se então a Conferência das Nações Unidas sobre Desertificação em 1977 em Nairóbi, Quênia, resultando em reconhecimento fundamental para subsidiar ações.

Neste sentido, muitos países começaram a prestar mais atenção a seus problemas ambientais. Como corolário do processo de conscientização, as regiões com climas áridos e semiáridos no mundo ganharam o palco das discussões. Os problemas recorrentes de pobreza e de meio ambiente necessitavam de um tratamento direto pela comunidade internacional. A relação entre esses dois fatores era muito forte para passar despercebida. Pobreza e degradação do meio ambiente representavam uma ameaça, e uma pressão sobre os países mais desenvolvidos, pois a migração por sobrevivência tornava-se uma realidade. As ações 
humanitárias se intensificaram para manter as populações afetadas em locais sob "controle", assistidas pelas Nações Unidas.

De fato, a ação humanitária da ONU com a criação dos campos de refugiados, permitindo a essas populações desenvolverem uma agricultura de subsistência, provou-se relativamente eficaz para confinar essas populações a áreas sob "controle" e monitoradas. O grande receio dos países desenvolvidos, e mesmo dos países em desenvolvimento da África, seria a migração predatória de bandos de miseráveis famintos e sem qualquer educação ou qualificação profissional para as periferias das suas regiões metropolitanas.

Em 1977, a Conferência das Nações Unidas sobre a Desertificação adotou o Plano de Ação de Combate à Desertificação. Embora a mobilização inicial da comunidade internacional tenha sido grande, os resultados práticos foram pífios. Isto foi constatado em 1991, quando o Programa das Nações Unidas para o Meio Ambiente (PNUMA) avaliou as ações empreendidas segundo o Plano de Ação. O PNUMA concluiu que o problema da degradação da terra no semiárido, árido e na região sub-úmida se intensificara, salvo raras exceções. Os resultados concretos em investimentos de recursos e de reversão dos processos de degradação foram modestos. Tal resultado deveria ser de certa forma esperado, na medida em que países com economias muito frágeis, em geral, baseadas em monocultura, e utilizando técnicas agrícolas tradicionais sem proteção do solo ou utilizando tecnologia, não teriam condições financeiras para arcar com ações de combate à desertificação sem uma robusta e contínua ajuda externa.

A avaliação global do status e do ritmo do processo de desertificação levou o PNUMA a constatar o insuficiente conhecimento de base sobre os processos de desertificação, o ponto nevrálgico para o seu efetivo combate. A capacidade das instituições existente é limitada, particularmente em países em desenvolvimento. Um sistema de observação integrado e coordenado baseado em tecnologia apropriada ao objeto de análise, cobrindo as esferas global, regional, nacional e local é essencial para se tomar medidas adequadas para se tratar com seca prolongada e desertificação e melhorar as condições sócio-econômicas dos espaços afetados.

Com os resultados dos esforços aquém das expectativas dos países que lideraram inicialmente o processo de combate à desertificação, estes propuseram a elaboração de uma convenção sobre o assunto durante a Conferência das Nações Unidas sobre o Meio Ambiente e Desenvolvimento, em 1992, no Rio de Janeiro, a Rio92.

Essa Conferência adotou uma nova abordagem, enfatizando ações para promover o desenvolvimento sustentável localmente, e requisitou à Assembléia Geral das Nações Unidas, 
o estabelecimento do Comitê Intergovernamental de Negociação para preparar, em meados de 1994, a Convenção para Combater a Desertificação, particularmente na África. Em 12/1992, a Assembléia Geral concordou e adotou a Resolução 47/188. O Comitê completou a negociação em 5 sessões e a Convenção foi criada em Paris em 17/06/1994, e aberta para assinatura dos países em 14-15/10/1994. Entrou em vigor em 26/12/1996. Mais de 179 países se tornaram Partes em março de 2002. A $1^{\text {a }}$ Conferência das Partes (COP), que é a instância maior de governança da Convenção, foi realizada em 1997. A partir de 2001, a COP passou a ser bienal, conforme lista a seguir:

COP 1, Roma-Itália de 29 de setembro a 10 de outubro de 1997

COP2, Dakar, Senegal, de30 de novembro a 11 de dezembro de 1998

COP3, Recife, Brasil, de 15 a 26 de novembro de 1999

COP4, em Bonn, de 11 a 22 de dezembro de 2000

COP5, Genebra, Suíça, de 1-12 de outubro de 2001

COP6, Havana, Cuba, de 25 de agosto a 5 de setembro de 2003

COP7, Nairobi, Quênia, de 17-28 outubro de 2005

COP8, Madri, Espanha, de 3-14 de setembro de 2007

COP9, Buenos Aires, Argentina, de 21 de setembro a 3 de outubro de 2009

COP10, Changwon City, Coréia do Sul, 10-21 de outubro de 2011.

COP 11, Windhoeck, Namíbia, 16-27 de setembro de 2013.

A Convenção conta com um Secretariado permanente com sede em Bonn (Alemanha), tem como órgão máximo de decisão a COP subsidiada pelo Comitê de Ciência e Tecnologia (CST) e pelo Comitê de Revisão da Implementação da Convenção (CRIC).

Em 1990, a Assembléia Geral das Nações Unidas estabelecera o Comitê Intergovernamental de Negociação para a Convenção-Quadro sobre Mudança do Clima. Este Comitê preparou a redação da Convenção e a adotou em 05/1992 na sede das Nações Unidas. A Convenção foi aberta para assinatura em junho de 1992, com 154 países signatários, e entrou em vigor em 21/03/1994. O Protocolo de Kyoto (1997) veio ao encontro das metas da Convenção do Clima. A $1^{\text {a }}$ COP reuniu-se em Berlim (Alemanha) em 1995. Em 1997, 165 países ratificaram ou aderiram a esta Convenção. (Câmara dos Deputados, 2005).

A Convenção sobre Diversidade Biológica (CDB), aberta para a assinatura durante a Rio92 entrou em vigor em 29/12/1993 e conta atualmente com 193 países. Tem um Secretariado permanente em Montreal (Canadá) e a COP é seu órgão máximo de decisão. Sob 
os auspícios da CDB foram negociados o Protocolo de Cartagena sobre Biossegurança (2003) e o de Nagoya em Acesso a Recursos Genéticos e a Repartição Justa e Eqüitativa dos Benefícios da sua Utilização aberto para assinatura em 2/2/2011 e que somente entrará em vigor em 2 anos. ${ }^{5}$

Portanto as Convenções sobre a Desertificação, a Mudança do Clima e sobre a Biodiversidade tiveram um início similar no seio das Nações Unidas, e cumprindo procedimentos análogos, porém seguiram trajetórias distintas quando deveriam ser complementares, caso o reconhecimento da natureza também climática da desertificação tivesse acontecido antecipadamente, ao invés de considerada apenas como impacto.

\section{4. $\quad$ Resultados da Rio92}

Um dos principais resultados da Rio92 foi o início do processo de negociação para a elaboração de três convenções ${ }^{6}$ :

Convenção das Nações Unidas de Combate à Desertificação nos países afetados por Seca Grave e/Desertificação, particularmente na África;

Convenção-Quadro das Nações Unidas sobre Mudanças Climáticas; e

Convenção das Nações Unidas sobre Biodiversidade Biológica. ${ }^{7}$

O documento mais importante aprovado na Rio92 foi a Agenda 21. É um ambicioso e abrangente plano de ação para se atingir o desenvolvimento sustentável. Não tem efetividade de um tratado, tampouco de declarações internacionais. O seu cumprimento representa mais uma obrigação moral dos Estados signatários, e por isso, não é ratificado, como as convenções. O Capítulo 12 da Agenda 21 foi denominado "Gestão de Ecossistemas Frágeis; combatendo a Desertificação e a Seca”. (13/08/1992). Atualmente, 191 países são signatários da Convenção de Combate à Desertificação, sendo que o Brasil tornou-se Parte em

\footnotetext{
${ }^{5}$ Entrevista de Bráulio Dias, Secretário Executivo da Convenção sobre Biodiversidade Biológica, Revista Veja, 30/01/2013, p. 13-15.

${ }^{6}$ Ver a definição de Convenção e Convenção-Quadro aplicadas ao meio ambiente em Dinh,N.Q.; Daillier, P.; Pellet,A. Direito Internacional Público, Fundação Calouste Gulbenkian, 2a Edição, p.1310-1311, 2003.

7 A Convenção de Combate à Desertificação nem é citada por especialistas em mudanças climáticas, como J. Marcovich em Desafios do clima no Brasil e no mundo, Política Externa, Vol18, No 4, Mar/Abr/Mai/2010, p.25 quando cita a Agenda 21 e menciona as Convenções do Clima e da Biodiversidade como foco dos grupos técnicos para aprovação das duas convenções da ONU. Não cita a Convenção de Combate à Desertificação aprovada na mesma ocasião.
} 
25/06/1997. A Agenda 21 Brasileira foi lançada em 2002 com ações prioritárias e 21 objetivos divididos em 5 blocos.

As áreas cobertas pela Convenção das Nações Unidas de Combate à Desertificação (UNCCD) abrangem 40\% das terras no mundo; 2 bilhões de pessoas, sendo $90 \%$ em países em desenvolvimento, com prevalência na África e Ásia (UNCCD, 2011). Segundo o Painel Intergovernamental sobre Mudanças Climáticas (IPCC), essas regiões serão as mais fortemente afetadas pelas alterações no clima mundial e, ainda assim, seus habitantes são subrepresentados em discussões, afirmou Antonio Magalhães, diretor da Conferência Internacional sobre Áreas Semiáridas e Áridas (ICID).

A Convenção das Nações Unidas de Combate à Desertificação (UNCCD), no seu Art. $1^{\circ}$ traz as definições necessárias para o entendimento de todos os atores envolvidos.

Por desertificação, entende-se a degradação da terra nas zonas áridas, semiáridas e sub-úmidas secas, resultantes de vários fatores, incluindo as variações climáticas e as atividades humanas.

Combate à desertificação diz respeito às atividades que fazem parte do aproveitamento integrado da terra nas zonas áridas, semi-áridas e sub-úmidas secas com: prevenção e/ou redução da degradação das terras; reabilitação de terras parcialmente degradadas, e recuperação de terras degradadas.

Embora as variações climáticas tenham sido incluídas no texto, a definição de combate à desertificação cobre somente as conseqüências das atividades humanas com foco na degradação da terra, por mau uso do solo.

Atualmente, a Convenção das Nações Unidas de Combate à Desertificação é o único instrumento internacional multilateral que pode contribuir para a conservação dos recursos naturais das terras áridas e semiáridas em todo o mundo. Tem por objetivo combater a desertificação e os efeitos da seca dentro de uma abordagem coerente com a Agenda 21, promovendo o desenvolvimento sustentável das áreas afetadas (Art. $2^{\circ}$ ).

Os países deverão ser dirigidos por princípios (Art. $3^{\circ}$ ) que incluem a necessidade de elaboração e implementação de programas de ação nacional de combate à desertificação com participação popular, e a realização de parcerias, cooperações e coordenações com entidades não governamentais.

A UNCCD estabeleceu obrigações gerais (Art $4^{\circ}$ ) para que os países empreguem abordagens integradas, considerando os aspectos físicos, biológicos e sócio-econômicos dos problemas e aliados a estratégias de erradicação da pobreza, e empreendendo esforços no 
combate à desertificação e mitigação dos efeitos da seca. Dentre as obrigações específicas dos países afetados $\left(\mathrm{Art5}^{\circ}\right)$, as prioridades são de combater a desertificação e promover a conscientização e a participação da população e das organizações da sociedade civil nos esforços do combate à desertificação.

A Convenção define que os propósitos dos Programas de Ação Nacional de Combate à Desertificação $\left(\right.$ Art. $10^{\circ}$ ) são a identificação dos fatores que contribuem para a desertificação e a elaboração de medidas práticas para combatê-la. O programa deverá determinar as obrigações dos atores (governo e sociedade civil) e os recursos necessários ao mesmo. $\mathrm{O}$ programa deverá integrar a estratégia de desenvolvimento do país; ser flexível para ajustar-se a mudanças ao longo do tempo; dar especial atenção a medidas preventivas; requerer acompanhamento e revisões periódicas; e proporcionar efetiva participação da sociedade civil e suas organizações no planejamento, mecanismos de decisão, acompanhamento e avaliação.

A Convenção enfatizou também a criação de sistemas de alerta precoce e de preparação da sociedade (preparação de planos de contingência) para o enfrentamento de secas, incluindo o fortalecimento de sistemas de segurança alimentar. Propugnou que as Partes deverão mobilizar recursos financeiros substanciais e facilitar, através de cooperação internacional, a transferência de tecnologia, conhecimentos gerais e técnicos para os países em desenvolvimento afetados.

\section{Desertificação no Brasil}

Seguindo uma das recomendações da UNCCD, o Brasil criou em 2004 um programa específico para tratar do assunto sob a coordenação do Ministério do Meio Ambiente (MMA). Na apresentação do Programa de Ação Nacional de Combate à Desertificação e de Mitigação dos Efeitos da Seca - PAN-Brasil - do MMA enfatizou-se que “(...)a desertificação é promovida por fatores climáticos aliados ao uso inadequado dos recursos naturais em áreas com ecossistemas frágeis e resulta de graves agressões ao meio ambiente, afeta substancialmente a qualidade de vida das comunidades residentes nas $\mathrm{ASD}^{8}$, reduzindo a fertilidade dos solos, perdas de reservas hídricas e de biodiversidade. Contribui também para a insegurança alimentar, a fome, a pobreza e pode dar origem a tensões sociais, econômicas e políticas”. (MMA, sem data).

\footnotetext{
${ }^{8}$ Áreas Susceptíveis à Degradação
} 
Várias articulações com a sociedade civil e instituições estaduais via parcerias estratégicas nacionais e internacionais foram realizadas com vistas a combater a desertificação e o tema passou a ser discutido em vários seminários no Brasil. Por exemplo, em agosto de 2002, realizou-se o Seminário Natureza e Sociedade nos Semiáridos, em Fortaleza-CE, e como parte de colaboração entre a Fundação Cearense de Meteorologia e Recursos Hídricos e o International Research Institute for Climate Prediction dos Estados Unidos da América. (Souza Fillho; Moura, 2006). Os organizadores do seminário chamaram a atenção sobre a recorrência do tema no que diz respeito ao desafio para as sociedades, associado a processos de mudança e variabilidade climáticas e degradação ambiental, em especial, o processo de desertificação, o aumento dos desequilíbrios regional e intra-regional e as questões sociais associadas à ocupação da terra e à questão agrária.

Os processos de desertificação têm nas mudanças do clima um forte agente agravante do seu aprofundamento na medida em que ocorrem em regiões muito carentes e submetidas à distribuição irregular das chuvas.

O Brasil, enquanto signatário da Convenção-Quadro das Nações Unidas sobre Mudanças Climáticas, comprometeu-se a formular, implementar, publicar e atualizar regularmente programas nacionais e regionais que incluam medidas para mitigar as mudanças do clima e para permitir a adaptação a essas mudanças. A área de adaptação às mudanças climáticas é a que menos recebeu atenção por parte das autoridades brasileiras, fazendo com que o Brasil apresente vulnerabilidades neste quesito. ${ }^{9}$ Por isso, as mudanças climáticas e as políticas públicas foram objeto de análise do Tribunal de Contas da União, órgão de assessoria ao Congresso Nacional. Os seguintes temas, no que diz respeito à adaptação, foram eleitos como prioridades em 2008 para suas auditorias: as zonas costeiras; a segurança hídrica do Semiárido e o setor de agropecuária.

A Conferência Internacional Clima, Sustentabilidade e Desenvolvimento em Regiões Semiáridas (ICID), segundo o seu diretor, é a única grande reunião que trata do desenvolvimento das regiões semiáridas no contexto das mudanças climáticas, e realizou sua segunda edição em 2010 em Fortaleza-CE. A 1 ${ }^{\text {a }}$ ICID, que também ocorreu em Fortaleza-CE em 1992, serviu para subsidiar a Rio92 com dados e informações científicas sobre as regiões no mundo, e a $2^{\mathrm{a}}$ serviu como Conferência preparatória para a Rio+20 em junho/2012. Com a

\footnotetext{
${ }^{9}$ A Lei no ${ }^{\text {1 }}$ 12.187/2009 que instituiu a Política Nacional sobre Mudanças do Clima definiu no seu Art.2 ${ }^{\circ}$ Inc. X, "vulnerabilidade: grau de susceptibilidade e incapacidade de um sistema, em função de sua sensibilidade, capacidade de adaptação, e do caráter, magnitude e taxa de mudança e variação do clima a que está exposto, de lidar com os efeitos adversos da mudança do clima, entre os quais a variabilidade climática e os eventos extremos."Seca prolongada é considerada pelos climatologistas um evento climatológico extremo.
} 
liderança do Brasil, representantes de 60 países foram mobilizados para discutirem ações focadas nos desafios e oportunidades que enfrentam as regiões áridas e semiáridas do planeta, quanto aos aspectos ambientais e climáticos, vulnerabilidades, impactos, respostas de adaptação e desenvolvimento sustentável. (CGEE, 2010).

A II Conferência Mundial UNCCD ocorreu em Fortaleza-CE de 4-7/02 de 2013. O foco temático recai sobre: a Avaliação Econômica da Desertificação; Gestão Sustentável do Solo e a Resiliência das Áreas Áridas, Semiáridas e Sub-Úmidas Secas. O evento cobriu dois subtemas: impactos econômicos e sociais da desertificação, e degradação dos solos e seca; e custos e benefícios das políticas e práticas abordando a desertificação, degradação da terra e da seca. Mais uma conferência internacional, com Fortaleza-CE hospedando novamente o evento. Resultaram algumas ações para apoio ao combate à desertificação na África, por exemplo, as que ajudam na questão da adaptação. Nesse sentido, são interessantes os projetos de reflorestamento e cultivo realizados por 20 países africanos da região subsahariana, e com apoio da Agência Panafricana da Grande Muralha Verde em parceria internacional com a França e mais recentemente com o Brasil, sob forma tripartite. Entretanto a luta diária por água para consumo e plantio ainda persiste.

\subsection{Mapeamento das áreas afetadas}

O Atlas das Áreas Susceptíveis à Desertificação (MMA, 2007) aponta o Semiárido brasileiro como área suscetível à desertificação. Para essa classificação, o MMA utilizou-se dos critérios indicados pela UNCCD.

O Nordeste brasileiro dispõe de apenas 3\% dos recursos hídricos do País, sendo que o Norte detém 68\%, o Centro Oeste 16\%, o Sul, 7\% e o Sudeste 6\%. (ANA/MMA, 2009). De fato, a região Nordeste conta com importantes bacias hidrográficas, como a dos rios São Francisco e do Parnaíba, além de possuir um razoável sistema de rios, o que poderia parecer paradoxal, quando se justifica a pouca disponibilidade apontada na distribuição percentual dos recursos hídricos pelas várias regiões geográficas brasileiras.

A questão é que muitos dos cursos d'água do Nordeste brasileiro não são perenes, correndo apenas na estação das chuvas, o que faz com que os efeitos da temporada da seca sejam intensificados, prejudicando a agricultura, que em geral, é de subsistência, e causando grandes transtornos à população local. Com o aumento da temperatura potencializado por mudanças climáticas e fenômenos naturais, a evaporação de água do solo é muito grande, destruindo-o como base para a plantação. Esses fenômenos que precisam de mais pesquisa 
para se conhecer como agem em conjunto, resultam em secas prolongadas, causando fenômenos climatológicos extremos com forte impacto sobre o solo, a agricultura, e a segurança alimentar de populações que já são carentes e também destruindo o meio ambiente. Ademais, as secas prolongadas concorrem para a erosão costeira que destrói construções, públicas e privadas, fenômeno que ocorre em Fortaleza, por exemplo, e que são objeto de pesquisas pois estão mais freqüentes e devastadores. As capitais do Nordeste na costa brasileira são laboratórios naturais para este tipo de pesquisa, e, busca por soluções favorecidas pela cooperação nacional e internacional. Segundo o Prof. Luís Parente da Universidade Federal do Ceará, a ausência de chuvas impede que os rios carreguem areia para o mar e as ondas, devido aos ventos fortes, aumentam a erosão nas encostas. E esclarece que: "O somatório destes dois fatores do período de estiagem são, nesse momento, preponderantes para a erosão que vem sendo observada ao longo do final de ano de 2012 e início de 2013.”

Experiências científicas contidas no Relatório de Clima do INPE apontam para o agravamento do déficit hídrico do Semiárido por alterações no regime de precipitação, com variações tanto espaciais quanto temporais, ocasionadas pela modificação da cobertura natural da Caatinga para deserto, em um processo de desertificação. (TCU, 2009). A propósito, os dados do Atlas Brasil, lançado pela Agência Nacional das Águas que mapeou as necessidades hídricas de 5.565 municípios brasileiros, concluiu que o Brasil precisa de mais de $\mathrm{R} \$ 22$ bilhões de investimentos para evitar essa escassez de água. Ademais as empresas de saneamento no Brasil não têm no seu planejamento, mesmo de longo prazo, planos a serem adotados no caso de uma possível mudança de padrão dos eventos climáticos. (DAE). Portanto, a falta de preparação do Brasil com relação às mudanças do clima não diz respeito apenas ao Semiárido.

O Semiárido brasileiro abrange 1.162 municípios de 10 estados, com uma área de cerca de $900.000 \mathrm{~km}^{2}$, cobrindo cerca de $8 \%$ do território nacional. Diferentemente de outras áreas semiáridas, onde a densidade geográfica é baixa, no Brasil, a região é habitada por cerca de 22 milhões de pessoas, enquanto que a Amazônia Legal, por exemplo, ocupa cerca de 60\% do território brasileiro e possui praticamente a mesma população. A vulnerabilidade do Semiárido brasileiro é grande, sobretudo com relação ao seu bioma principal, a Caatinga, que é único na Terra, e, portanto, dispõe de uma biodiversidade que não existe em outro lugar do planeta. A preocupação quanto à conservação desse bioma não é sem motivo. Fonte de recursos como madeira, carvão, material para construção, carnes, frutas, plantas medicinais, fibras, mel e forragem para os rebanhos, a Caatinga necessita de cuidados especiais. 
Esse bioma recebeu um reforço importante com a implantação do Instituto Nacional do Semiárido (INSA), criado em 2004, instituição de pesquisa do Ministério da Ciência, Tecnologia e Inovação (MCTI), localizado em Campina Grande-PB, mas que não conseguiu visibilidade nacional, tampouco apoio institucional que o consolide e o faça desempenhar o papel para o qual foi criado.

O Projeto de Lei 2447/2007 que institui a Política Nacional de Combate e Prevenção à Desertificação e Mitigação dos Efeitos da Seca e criou um sistema foi aprovado na Comissão de Agricultura, Pecuária, Abastecimento e Desenvolvimento Rural da Câmara dos Deputados em 29/10/2008. Após receber solicitação de urgência urgentíssima em 24/04/2013 por parte da Deputada Manuela D’Àvila do PcB/RS. A matéria não foi apreciada em face do encerramento da sessão. Esse PL ainda não foi aprovado no Congresso, embora tenha entrado para tramitação em regime de prioridade em 2007, o que demonstra a total falta de interesse do Governo Brasileiro sobre o tema. A área também não conta com um fundo próprio para apoio a projetos de pesquisa e desenvolvimento. Por outro lado, em 29/12/2009 a Política Nacional de Mudanças do Clima foi criada em tempo recorde, incorporando o compromisso voluntário do Brasil de redução das suas emissões, apresentado na COP 15 da Convenção do Clima em 12/2010, e um fundo específico (Fundo Nacional sobre Mudança do Clima-Fundo Clima) criado no final de 2009, regulamentado em 2010 e coordenado pelo MMA, envolvendo inclusive o BNDES, demonstrando prioridade da agenda mudanças climáticas no Brasil.

Entretanto, com os problemas de desertificação se agravando, e exigindo ações que realmente se concretizem, em mais uma tentativa de reforçar, em nível governamental, o suporte ao combate à desertificação, o MMA e o MCTI criaram a Rede sobre Desertificação do Semiárido Brasileiro - Rede Desertificação, com duração de seis anos para ser financiada com recursos do Fundo Clima. Esta rede não foi implementada em 2009 por falta de recursos financeiros, pois o Fundo Clima somente foi regulamentado e entrou em funcionamento no final de 2010, e a iniciativa perdeu o "momentum".

Não há um aparato legal e institucional efetivo e consistente para apoiar a implementação do Programa de Ação Nacional de Combate à Desertificação e Mitigação dos Efeitos da Seca que deveria nortear as ações governamentais e não governamentais e buscar cooperação com outros atores. O que se observa é que falta coordenação dos programas governamentais e planejamento que evite a pulverização de recursos, responsabilidade que caberia à Comissão Nacional de Combate à Desertificação. O Governo Brasileiro adotou a descentralização como meio para implementar as ações observando as especificidades locais e 
para assegurar a participação popular no enfrentamento da seca e da desertificação, o que foi uma boa iniciativa, mas sem uma integração dos programas governamentais e as ações locais. Das obrigações da UNCCD, o Brasil efetivou algumas, dentre elas, a criação de um sistema de alerta precoce (SAP) com o Instituto Nacional de Pesquisas Espaciais (INPE), unidade de pesquisa do Ministério de Ciência, Tecnologia e Inovação.

\section{A questão da água e do ciclo hidrológico com a desertificação}

O grande ciclo da água mostra a distribuição em volume dos seus componentes. (WBCSD \& PNUMA, 1998). Este ciclo é fundamental na formação do clima, suas mudanças e seus extremos, como a desertificação:

Vapor d'água na atmosfera $-13.000 \mathrm{~km}^{3}$

Evaporação da água na terra $-70.000 \mathrm{~km}^{3}$

Precipitação sobre a terra $-119.000 \mathrm{~km}^{3}$

Precipitação sobre o mar - 390.000km³

Evaporação da água no mar - $430.000 \mathrm{~km}^{3}$

Enxurradas em terra - $40.000 \mathrm{~km}^{3}$

Lagos- 9,1 milhões de km³

Rios $-22.000 \mathrm{~km}^{3}$

Águas subterrâneas - 10 milhões $\mathrm{km}^{3}$

Oceanos - 1.338 milhões $\mathrm{km}^{3}$

Segundo a Agência Nacional das Águas, em muitos países em desenvolvimento, a irrigação é responsável por $90 \%$ da água extraída das fontes disponíveis. Enquanto na Inglaterra, onde há chuvas abundantes o ano inteiro, a água usada na agricultura responde por menos de 1\%. Na Espanha, Grécia e Portugal excede 70\% do uso total.

A água doce equivale a menos de $3 \%$ de toda a água do planeta, sendo que o restante é constituído por água dos oceanos e, por isso, não potável. Destes 3\%, mais de 2,5\% está congelada na Antártica, no Ártico e em geleiras, não disponível para o uso humano. A dessalinização da água do mar é um processo ainda muito dispendioso. Assim sendo, todas as necessidades de água doce para o homem e os ecossistemas dependem de 0,5\% de água doce disponível no planeta. 
Os $0,5 \%$ estão localizados em:

10. $000.000 \mathrm{~km}^{3}$ armazenados em aqüíferos;

$119.000 \mathrm{~km}^{3}$ sob a forma de chuvas, depois de descontada a evaporação;

$91.000 \mathrm{~km}^{3} \mathrm{em}$ lagos naturais;

Mais de $5.000 \mathrm{~km}^{3}$ em instalações para armazenamento construídas pelo homem reservatórios. Um aumento de 7 vezes a capacidade global de armazenamento desde 1950; e $2.120 \mathrm{~km}^{3}$ em rios- repostos com as chuvas e o degelo de neve e gelo.

Segundo especialistas em recursos hídricos “(...) o mundo não está "ficando sem água” o problema é que a água não está sempre disponível quando e onde o homem precisa. $\mathrm{O}$ clima, variações sazonais, secas e enchentes contribuem para condições locais extremas" (FOSTER \& CHILTON, 2003). Ademais, menos de 10 países concentram $60 \%$ do suprimento global de água doce disponível: Brasil, Rússia, China, Canadá, Indonésia, EUA, Índia, Colômbia e Congo, com variações locais muito significativas.

\section{Conclusões}

Tempo e clima; ar, água, seus ciclos e interações com outros elementos, a grande circulação atmosférica da Terra, além das atividades econômicas, portanto componentes naturais e as resultantes da ação humana precisam ser analisadas em conjunto. Em mão dupla, pois suas ações resultam em problemas ou em vantagens para os que souberam conduzir o desenvolvimento de suas nações em bases equilibradas com a natureza e o universo, sendo estes, muito mais do que o meio ambiente.

Em mais uma tentativa de atacar o problema causado pela desertificação, e em analogia à Década da Água, a ONU lançou em 2010 a Década para os Desertos e a Luta contra a Desertificação (2010-2020). Um esforço de 11 anos para sensibilizar e estimular ação por uma maior proteção e melhor manejo das terras secas do mundo, lar de $1 / 3$ da população mundial que enfrenta sérias ameaças ambientais, sociais e econômicas. Nas palavras do Secretário Geral da ONU Ban Ki-moon ao anunciar o lançamento “...comprometemo-nos a intensificar os nossos esforços para cuidar da terra de que necessitamos para implementar os Objetivos de Desenvolvimento do Milênio e garantir o bem-estar humano.” 
Na COP-10 sobre a Desertificação na Coréia do Sul em 10/2011, o Brasil se posicionou contra a criação de um mandato global com foco na degradação de terras. A propósito, e segundo Francisco Campello, diretor de Combate à Desertificação do Ministério do Meio Ambiente "há uma resistência porque o tema "degradação de terras" sai do foco da UNCCD e já é abordado em outras convenções". A UNCCD atua no combate à desertificação nas terras áridas e semiáridas, com especial atenção para a África, completa o representante do MMA. O que está em jogo são os recursos financeiros a serem destinados aos países atendidos pela UNCCD como receptores desses ativos. Degradação de terras existe praticamente no mundo inteiro, mesmo nas regiões que não são áridas ou semiáridas dos países desenvolvidos e que por isso fogem do alvo da UNCCD e desvirtuam o seu objetivo. Certamente, os países doadores, a maior parte de países desenvolvidos e em crise financeira desde 2008 não aceitam, tacitamente, pelo menos, por exemplo, a participação da China, $2^{\mathrm{a}}$ economia mundial, como país em desenvolvimento e, por isso, receptor dos recursos financeiros da UNCCD.

Ao presidir uma reunião do Conselho Nacional de Recursos Hídricos em 2009, o então Ministro de Meio Ambiente, Carlos Minc, comentava sobre a Conferência das Partes da Convenção de Combate à Desertificação que seria realizada em setembro do mesmo ano, a COP9, e a denominou a "COP dos pobres". No mesmo ano, em dezembro, foi realizada a COP15, a de Mudanças Climáticas, levando a Copenhague delegações nacionais enormes, políticos, especialistas de todas as áreas, jornalistas, uma centena de chefes de Estados e de Governos, organizações não governamentais, curiosos, um evento com cobertura total da mídia internacional como jamais se havia visto em uma COP. Em 2010, na COP 10 da Biodiversidade, um Plano Estratégico com 20 novas metais globais e as metas de Aichi foram definidos, estas com muito pouca repercussão na mídia.

A Convenção de Combate à Desertificação das Nações Unidas (UNCCD) é o único acordo internacional legalmente vinculante que cria a relação entre meio ambiente, desenvolvimento e a promoção de solos sustentáveis. Responde, em princípio, às Metas de Desenvolvimento do Milênio até 2015, como salientou Ban Ki-moon. Esta integração, única na UNCCD, tem sido uma aspiração das Nações Unidas quando da realização das suas conferências de meio ambiente, priorizada mais uma vez na pauta da Conferencia das Nações Unidas sobre Desenvolvimento Sustentável, a Rio+20. A seca e a desertificação estão conectadas às questões sociais, tais como pobreza, deficiência sanitária e nutricional, insegurança hídrica e alimentar e migração. Em virtude do seu conceito original, o objetivo da UNCCD, explícito em seu art. $2^{\circ}$, recomenda uma abordagem integrada com a Agenda 21, 
visando contribuir para o desenvolvimento sustentável nas regiões afetadas, e com os demais acordos internacionais.

Das três convenções das Nações Unidas aprovadas na Rio92 apenas a de Mudanças Climáticas conseguiu avançar. Uma das causas foi que Mudanças Climáticas, embora sem um fundo específico até 2009, pelo menos no Brasil, onde foi aprovado e regulamentado em 2010, conseguiu implantar um braço econômico representado pelo mercado do carbono e o Mecanismo de Desenvolvimento Limpo, sendo o Brasil pioneiro nesta iniciativa, apesar de ter perdido terreno para a China e a Índia, em termos de valor total dos projetos.

A Convenção da desertificação avançou muito pouco e sem um componente econômico para lhe dar sustentação. Não tem visibilidade na mídia, nem agenda com forte apelo como a Convenção sobre Mudanças do Clima e o protocolo de Kyoto que tratam de um problema global e mais importante que qualquer outro de caráter global, como a mídia fez questão de disseminar.

A Convenção de Biodiversidade encontrou várias dificuldades para ser implementada, e em especial no Brasil, quanto ao seu aspecto econômico, qual seja a de produzir uma variedade de novos fármacos de valor comercial no país de maior biodiversidade do mundo. A propósito, US\$ 5 bilhões/ano deixam de ser gerados pelo Brasil com fitoterápicos, e atualmente o País dispõe de apenas uma droga desse gênero baseada na flora nativa. A Alemanha detém 28\% do mercado de fitoterápicos, o Japão 17\%, a França, 13\%, $12 \%$ para o restante da Europa, $11 \%$ para a América do Norte, $18 \%$ para outros e $1 \%$ para o Brasil. ${ }^{10} \mathrm{O}$ G7, o grupo dos países mais industrializados do mundo, e em especial a Alemanha, mostramse muito interessados nas riquezas naturais das florestas tropicais do mundo, em especial a amazônica, e inclusive apoiou por anos a fio o PPG7 (Projeto Piloto de Proteção das Florestas do G7) no Brasil. Mais recentemente, o Fundo Amazônia foi financiado com doação da Noruega no valor de cerca de 1 bilhão de dólares e tendo como gestor o BNDES, e será necessário avaliar a sua implementação e os resultados dos projetos futuramente. A facilidade de transformar pesquisa em inovação colocou a Alemanha em primeiro lugar no ranking da produção de fitoterápicos.

No orçamento da União para o Governo Federal constante do Plano Plurianual (PPA) 2012-2015, o Programa de Combate à Desertificação não foi incluído, o que significa que a questão da desertificação será apoiada por uma ação de Mudanças Climáticas cuja meta será atualizar o Plano de Ação Nacional de Combate à Desertificação e Mitigação dos Efeitos da

${ }^{10}$ Folha de São Paulo, País deixa de gerar US\$ 5bi por ano com fitoterápicos, p.A18, 07/06/2010. 
Seca (Programa 2050 - Mudanças Climáticas) sob a coordenação do MMA. Programas específicos para Biodiversidade e Mudanças Climáticas foram mantidos no novo PPA, demonstrando, assim, a importância dada pelo atual governo às questões da desertificação, um plano inferior em relação às demais convenções de meio ambiente.

A desertificação, sob o ponto de vista da política e da geopolítica, está relacionada a um universo da população nacional e mundial pobre ou miserável, excluída do mercado de consumo, do desenvolvimento nos padrões aceitáveis pelo mundo desenvolvido globalizado, e sem qualquer interesse dos países mais desenvolvidos em tê-los como parceiros ou mesmo competidores. Esses países estão fora do mercado financeiro e comercial global. Este diagnóstico é bem conhecido e foi ele que respaldou, de fato, as discussões sobre o assunto até hoje. Os países mais afetados pela desertificação carecem de infraestrutura para enfrentar tanto a seca meteorológica - períodos de escassas chuvas- como a hidrológica - de longos períodos de tempo sem precipitações, e a seqüela extrema, a aridez. Faltam-lhes técnicas adequadas e tecnologia e a pobreza impede a sua aquisição. A incapacidade dos estados afetados de se protegeram para conseguir em pouco tempo os meios para mitigar a tragédia, assunto essencial e diverso que se lhe propõe aos países mais pobres, e com o qual se esclarece que o problema não é somente uma disputa com a natureza, é bem mais profundo.

Os países mais afetados, - os africanos, tem dificuldade de se organizar entre si, em uma espécie de pan-africanismo de combate à desertificação. Muitas dessas nações tendo ainda limitado o seu grau de organização interna, alguns sendo formados por reunião de tribos e clãs e não raramente em disputas sangrentas.

Se nem os países diretamente afetados conseguem uma liderança ou encontram soluções locais que aproveitem economicamente os produtos dos biomas e sistemas envolvidos com a questão da desertificação, embora representando $35 \%$ da população mundial, qual a sua representatividade nos mercados globalizados? Qual o seu poder de barganha? Some-se a estes problemas, a pobreza extrema e as condições políticas presentes na realidade de alguns desses países, onde proliferam guerras tradicionais que alimentam um mercado de armas financiado por países desenvolvidos em conjunto com comércio de drogas; muita corrupção, pouca democracia e falta de respeito aos direitos humanos e ambientais e nenhum ou pouco conhecimento científico e tecnológico. A situação é grave na medida em que em vários dos países africanos, a mobilidade de pesquisadores no seu território é considerada perigosa e inibe a cooperação internacional. A propósito, um dos projetos apoiado pela França e Brasil para combate à desertificação na África a ser desenvolvido na 
Nigéria, embora bem avaliado cientificamente foi impedido de ser realizado por falta de segurança física dos pesquisadores estrangeiros.

Se as questões relacionadas à biodiversidade ainda são consideradas complementares às de mudanças climáticas uma vez que podem resultar em aquecimento global e ter impacto sobre ecossistemas e biomas que abrigam flora e fauna, colocá-las sob ameaça, os problemas da desertificação se reduziram, na prática, ao mau uso do solo pelo homem, um problema de degradação ambiental.

Essas duas dimensões dizem respeito à ação do homem sobre o meio ambiente e suas consequiências ao longo do tempo. Esse ponto é coerente com as abordagens adotadas pelos ambientalistas e suas políticas de proteção ao meio ambiente. As questões relacionadas à ação do ambiente e também do meio-ambiente sobre o homem, aí incluídas, as mudanças climáticas produzidas por variabilidade natural do clima, cuja compreensão é essencial para a adaptação dos seres vivos, não são conhecidas, ou não são consideradas importantes o suficiente para ter prioridade em termos de ações no âmbito das Convenções das Nações Unidas e das políticas nacionais.

A questão da desertificação foi tratada como um problema de meio ambiente desde o início, ou seja, a partir dos anos 70, e por isso, o PNUMA liderou todo o processo, e no Brasil, conduzida pelo MMA. A Organização Mundial de Meteorologia (OMM), criada em 1950 como a agência especializada das Nações Unidas para tratar do tempo, clima e água, somente teve papel importante quanto aos temas das três convenções, na criação em 1988 do Painel Intergovernamental de Mudanças Climáticas (IPCC), que não é da ONU, em conjunto com o PNUMA. O contexto no qual o debate sobre desertificação evoluiu foi marcado pelo crescimento da ecologia e das políticas ambientalistas nos anos 80/90 que passaram a dominar grande parte das políticas nacionais e da internacional. Por falta de conhecimento científico sobre as causas da desertificação, o problema foi tratado como de degradação do meio ambiente, desprezando-se, na prática, um aspecto fundamental - o climático, e provocando, assim, atrasos importantes na elaboração de políticas e de ações de adaptação às mudanças climáticas. Ademais, a estrutura proposta pela ONU de construção de consensos está completamente ultrapassada, afirma Eduardo Viola da Universidade de Brasília, que completa “...o mundo está dividido e o Brasil também não quer avançar na construção de uma governança ambiental global."

\footnotetext{
${ }^{11}$ Folha de São Paulo, Impasses políticos globais devem levar conferência a fiasco, p. C10, 22/05/2012.
} 
A Convenção da Desertificação foi montada de cima para baixo, ou seja, das Nações Unidas para os países afetados, embora respondendo necessidades destes. Portanto, muitos dos países afetados não construíram políticas nacionais, emanadas de anseios do povo e de vontade política de seus governantes, até porque não possuem condições nem quadro institucional para implementar as recomendações das Nações Unidas.

Com relação à Convenção do Clima, houve uma evolução em nível interno por parte dos Estados participantes em termos de engajamento, o que não ocorreu com outros acordos multilaterais. Além da Convenção, o tema teve o impulso de um acordo internacional de grande porte, o Protocolo de Kyoto, criado em 1997(SILVA, 2009).

A COP17 (Mudanças Climáticas) de 12/2011 conseguiu avançar as negociações pois, pela primeira vez, os maiores poluidores do mundo, EUA e China integrarão o mesmo acordo, porém Japão, Canadá e Rússia estarão ausentes na renovação do Protocolo de Kyoto, o que em princípio, é uma atitude estranha por parte do Japão, mas com explicações geopolíticas. Segundo John Broder do New York Times, “O que realmente está em jogo aqui é a política em sua escala mais ampla, as relações entre EUA, Canadá, Japão e três potências econômicas em ascensão: China, Índia e Brasil.”. ${ }^{12}$

É bem conhecida a influência da mídia sobre o público. O efeito da ação da mídia pode ser verificado quando foram realizadas a COP9 e a COP15 em 2009, e é interessante constatar o espaço que a mídia nacional e internacional concedeu a uma e à outra. A primeira é a COP da Desertificação, e a segunda, a das Mudanças do Clima. A primeira diz respeito a mudanças do clima também, embora isto não seja divulgado, na medida em que a desertificação é um fenômeno climático extremo provocado por mudanças do clima, mas ocorrendo nas regiões mais pobres do mundo, a Semiárida, a Árida e a Sub-úmida, com povos sobrevivendo da compaixão de organizações humanitárias, e expostas a todo tipo de degradação, desde a do meio ambiente até a humana.

O grande desafio que se coloca é como exigir o cumprimento por parte dos dirigentes dos países signatários com relação aos artigos da Convenção de Combate à Desertificação de países que tem um Índice de Desenvolvimento Humano (IDH) medíocre? Qual o grau de articulação possível em nível político entre "parceiros" tão distintos, e com grau de desenvolvimento tão distante? Com quem fazer aliança no plano internacional? A estratégia do Brasil é procurar parceiros para aumentar o seu poder de barganha na arena internacional, inclusive para poder defender seus interesses na Convenção do Clima. Para tanto, procurou

\footnotetext{
${ }^{12}$ Folha de São Paulo, Conferência do clima tem avanço histórico. Análise Debate climático envolve raízes da política global e afeta economia, p. C8, 12/12/2011.
} 
aliar-se aos países-ilha, as grandes vítimas da subida dos oceanos por aquecimento global, com vistas a conter a venda de créditos de carbono para algumas atividades que não estão contempladas no mercado formal do Protocolo de Kyoto, como a captura e o armazenamento de gás carbônico. Para fortalecer a aproximação entre os aliados, o Brasil criou em um mês 7 representações diplomáticas em pequenas nações insulares. ${ }^{13}$

Da mesma forma, após reconhecerem as dificuldades de reuniões com número muito grande de participantes e com interesses não-convergentes, alguns países em desenvolvimento regionalizaram suas ações. Como a solução dos problemas por meio de Conferência multilateral sobre desertificação não tem avançado, grupos de países tendem a se unir utilizando acordos bilaterais para formalizar parcerias internacionais. Este é o caso dos Países da América do Sul (UNASUL) com os Países Árabes (ASPA) ${ }^{14}$ após decisão tomada em reunião da UNCCD em São Paulo e Buenos Aires em 2009.

O documento "The Future We Want"15 saído da Conferência da ONU Rio+20 (junho/2012), focada no desenvolvimento sustentável e na erradicação da pobreza, com a participação majoritária dos países em desenvolvimento e numericamente insignificante dos países desenvolvidos, destaca a importância das três Convenções da ONU criadas por ocasião da Rio92. Apesar de ser mais uma Carta de Intenções, como todos os textos de política internacional multilateral a serem seguidas por ações, em um dos muitos subitens do item "Áreas temáticas e questões transversais" do citado documento a Desertificação e a degradação da terra e seca (parágrafos 205 a 209) são enfatizados. Reitera a importância da cooperação através de troca de informações de tempo e clima e provenientes de sistemas de alerta precoce relacionados à desertificação, degradação de terra e seca, tão bem como de tempestades de poeira e areia em nível global, regional e sub-regional.

A questão estratégica do combate à desertificação está intimamente ligada à resiliência e à adaptação das populações às mudanças cíclicas (ou não) do clima, e medidas urgentes precisam ser implementadas no âmbito da Convenção das Nações Unidas sobre a Desertificação, em conformidade com seu Plano de Ação 2008-2018 para salvá-la. Vários são os exemplos de sucesso de populações que se adaptaram ao seu ambiente, adotando padrões econômicos, valores sociais, culturais, humanos e éticos próprios, sem seguir os modelos de

\footnotetext{
${ }^{13}$ Folha de São Paulo, Brasil faz 'embaixadas do clima’ em países-ilhas, Ciência, p. 9, 19/06/2010.

14 UNASUL é a União das Nações Sul-Americanas e ASPA é a Cúpula América do Sul-Países Árabes, e é um mecanismo de cooperação bi-regional e um fórum de coordenação política, reúne 22 países árabes e 12 sul-americanos. Reunião dos Pontos Focais Sul-Americanos da UNCCD para desenvolver Agenda de Cooperação no Âmbito da ASPA ocorreu em São Paulo em 4/12/2009. Reunião da ASPA do Comitê de Cooperação Ambiental à margem da 9a COP/UNCCD foi realizada em Buenos Aires em 26/9/2009.

15 "The Future We Want", 49 páginas, consulta ao Google em 20/06/2012
} 
desenvolvimento dos países industrializados, muitas vezes perversos e predatórios, ilustrados pela história econômica mundial.

Os povos das florestas que não foram submetidos a profundos processos de aculturação; os dos desertos mais antigos, e os habitantes das áreas geladas da Terra aprenderam a lição da resiliência e da adaptação bem mais cedo do que os que lutam uns com os outros por valores questionáveis. A adaptação às mudanças climáticas não é resignação ou falta de atitude. Ao contrário, demanda muita ação e cooperação de todos, e respeito aos valores conquistados ao longo de séculos de adaptação bem sucedida de alguns povos a ambientes hostis do ponto de vista de alguns países desenvolvidos.

\section{Referências}

AGÊNCIA NACIONAL DAS ÁGUAS/(ANA/MMA), Fatos e Tendências, 2009

BJORGO, E. Commercial Observations Satellites- At the Leading Edge of Global Transparency, Ed. Baker,J.C.; O'Connel,K.M.;Williamson, R.A., Rand and ASPRS, p.415, 2001.

CENTRO DE GESTÃo E ESTUdOS ESTRATÉGIOS - CGEE - Ministério da Ciência e Tecnologia- ICID 2010, Notícias. CGEE, Ano III, Nº 11, Brasília, Maio/Junho/2010.

COMISSÃO DO MEIO AMBIENTE E DESENVOLVIMENTO SUSTENTÁVEL, Convenção-Quadro sobre Mudança do Clima e Protocolo de Kyoto, Plenarium, Editora da Câmara dos Deputados, Brasília, p.11, 2005.

FOSTER and CHILTON, Groundwater - the process and global significance of aquifer degradation, Royal Society of London, 2003

MINISTÉRIO DO MEIO AMBIENTE (MMA), 2007.

MINISTÉRIO DE MEIO AMBIENTE, Convenção das Nações Unidas de Combate à Desertificação, livro, 171 páginas, sem data.

SOUZA FILHO, F.A.; MOURA, A.D. ( organizadores) Memórias do Seminário Natureza e Sociedade nos Semi-áridos, 332 páginas, 2006.

REVISTA DAE, publicação da SABESP, As controvérsias sobre as mudanças climáticas e o saneamento, p. 4-5, maio 2011.

SILVA, D.H. da, Protocolos de Montreal e de Kyoto: pontos comuns e diferenças fundamentais. Revista Brasileira de Política Internacional, V. 52, p. 154-172, 2009. 
TRIBUNAL DE CONTAS DA UNIÃO (TCU) Auditorias de natureza operacional sobre políticas públicas e mudanças climáticas -Relatório Segurança Hídrica no Semiárido, p.19 outubro/2009.

WBCSD \& PNUMA. Industry, Fresh Water and Sustainable Development, 1998. 